\title{
Feasibility Analysis of the Stereo-teaching Mode in Public PE Selective Courses of Civilian-run Colleges and Universities in Hubei Province
}

\author{
Jing Li \\ Wuhan Technology and Business University \\ Wuhan, China 430000
}

\begin{abstract}
With the rapid national reform of the teaching system, each civilian-run college begins to make new reformatory attempts in various teaching activities. The research in this article is based on the mode construction of public PE selective courses of civilian-run colleges and universities in Hubei Province. In view of the problems in current teaching of public PE selective courses, the related analysis of feasibility and organization guarantee of its implementation made for stereoteaching of public PE selective courses of civilian-run colleges and universities in Hubei Province, aims to make a thorough inquiry of the mode of public PE selective courses that suits the students of civilian-run colleges and universities, providing some practical references for the reform of civilian-run colleges and universities.
\end{abstract}

Keywords—civilian-run colleges and universities; stereoscopic; public pe selective courses

\section{RESEARCH OBJECT AND METHOD}

\section{A. Research Object}

This article takes the regular undergraduate universities directly under the Education Department of Hubei Province as the research object.

\section{B. Research Method}

1) Literature consultation: We carefully went through books, such as Theory of Physical Education, School Physical Education Theory, Psychology of Physical Education, Research on the Reform and Construction of Public Physical Education Selective Course System in Higher Vocational Colleges and Brief Teaching Theory of Public Physical Education Selective Courses. Meanwhile, we searched numerous references from journal nets such as China Journal Net, VIP Journal Net and Wanfang Data, which laid a substantial theoretical foundation for this study.

2) Questionnaire method: In order to collect some true and effective data information, according to the design principle and method of questionnaire, two different kinds of questionnaires were designed for teachers and students in this article under the guide of experts.
3) Mathematical statistics Method: We did some statistical analysis on large amounts of data collected by questionnaires on some related statistical software like Excel, and we generalized and summarized the data to draw a corresponding conclusion.

\section{INTERPRETATION OF STEREO-MODE OF PUBLIC PE SELECTIVE COURSES}

\section{A. Definition of Stereo-Mode of Public PE Selective Courses}

Stereo-mode is a teaching form of Public PE Selective Courses, but not a fixed mode.

The definitions of stereo-mode, analyzed from different angles, are different too. In a stereo-mode, we can arrange different teaching contents according to different teaching goals. It presents a diversified form of development.

On the basis of synthesizing various theories, the stereomode of public PE selective courses put forward in this study refers to a mode which is established with the classroom teaching as the center and extracurricular multi-auxiliary and takes the extracurricular physical exercise in its credit management system.

\section{B. Explanation of Stereo-Mode of Public PE Selective Courses}

Specifically, a part of physical education classes adopt new teaching methods that are distinguished from old methods, such as classroom teaching activities based on point mode, discussion mode and group mode, which is aimed at improving the learning initiative of students and developing classroom effect.

Other physical education classes are directed by colleges to hold small but diversified extracurricular sports activities which are corresponding to course teaching and are guided by professional teachers in an organized way, including various special sports activities like morning exercise and activities held by sports association. It requires students to meet the requirements or to pass the examinations. Then students will be given some credits. The mode that combines classroom teaching with extracurricular exerc ise comes true. 


\section{RESULTS}

A. Investigation and Analysis on the Current Situation of Arranging Physical Education Courses in Civilian-Run Colleges and Universities in Hubei Province

1) Course projects: The projects of physical education courses, set up by 8 civilian-run colleges we investigates, all contains basketball, football, track and field, table tennis, volleyball and other traditional sports items "Table I". The proportion of badminton, billiard ball and other projects like that is less than that of traditional sports, influenced by the hardware facilities of physical education and the qualification of teachers. A minority of colleges are able to keep up with the development of sports items. They follow the social trends to set up yoga, cross-country orienteering and other new ite ms in physical education courses, which present the sociality and advancement with the times of physical education teaching.

TABLE I. PROJECTS OFPHYSICAL EDUCATION COURSES SET UP By 8 CIVILIAN-RUN COLLEGES

\begin{tabular}{lll}
\hline \multicolumn{1}{c}{ Projects } & Amount of Colleges & Proportion \\
\hline Basketball & 8 & $100 \%$ \\
Football & 8 & $100 \%$ \\
Trace and Field & 8 & $100 \%$ \\
Volleyball & 8 & $100 \%$ \\
Aerobics & 8 & $100 \%$ \\
Table Tennis & 8 & $100 \%$ \\
Martial Arts & 7 & $87.5 \%$ \\
Badminton & 4 & $50.0 \%$ \\
Yoga & 2 & $25.0 \%$ \\
Free Combat & 3 & $37.5 \%$ \\
Cross-country Orienteering & 3 & $37.5 \%$ \\
Taekwondo & 4 & $50.0 \%$ \\
\hline
\end{tabular}

2) Course modes: From "Table II", we can see that the modes of physical education courses of 8 civilian-run colleges relatively focus on "three-segment type" and "collateral type". 6 colleges, which account for $75 \%$, set up basic physical education courses in freshman year and set up selective courses in sophomore and senior year. 2 colleges, which account for $25 \%$, set up both basic physical education courses and selective courses simultaneously in freshman and sophomore year.

TABLE II. MODES OFPHYSICAL EDUCATION COURSES OF 8 CIVILIANRUN COLLEGES

\begin{tabular}{llll}
\hline \multicolumn{1}{c}{ Course Modes } & $\begin{array}{c}\text { Amount of } \\
\text { Colleges }\end{array}$ & Proportion \\
\hline Three-segment Type & 6 & & $75 \%$ \\
Collateral Type & 2 & & $25 \%$ \\
\hline
\end{tabular}

3) Teaching form: The teaching forms of 8 civilian-run colleges are basically the same and all adopt classroom teaching. They use the three-base type vertical teaching mode and limit the class size (Table 3). Basically, they employ the method that who selects first can get the opportunity, to arrange the class. Students' extracurricular sports activities are in a total "free" condition. The physical education teachers will not get involved in basically. This teaching form is a typical traditional mode (Russian Mode), which can hardly arouse students' enthusiasm for sports.
TABLE III. TEACHING FORMS OF PHYSICAL EDUCATION COURSESOF 8 CIVILIAN-RUN COLLEGES

\begin{tabular}{llll}
\hline & Teaching Forms & $\begin{array}{c}\text { Amount of } \\
\text { Colleges }\end{array}$ & Proportion \\
\hline Class & Classroom Teaching & 8 & $100 \%$ \\
Form & ExtracurricularT utorship & 0 & $0 \%$ \\
& Classroom & 0 & $0 \%$ \\
& Teaching+Extracurricular & & \\
Class & Tutorship & 8 & $100 \%$ \\
Number of & Limited Class Size & 0 & $0 \%$ \\
Students & Unlimited Class Size & & \\
\hline
\end{tabular}

\section{CONCLUSION AND ANALYSIS}

A. The School Running Features of Civilian-Run Colleges and Universities in Hubei Province Are Obvious. the Funds Are Guaranteed, Equipment and Facilities Are Complete, Structure of Teaching Staff Is Reasonable, Which Presents A Basic Guarantee for Implementing Stereo-Mode of Public PE Selective Courses

The features of civilian-run colleges and universities in Hubei Province are as follows.

- The funds of running school are social pooled and guaranteed: The funds of running school of civilianrun colleges and universities in Hubei Province are mainly social pooled by contraction party or individuals. The tuition of students is an important funding approach for civilian-run colleges operating. The source of students is a key factor that affects the development of civilian-run colleges. And the source of students of civilian-run colleges in Hubei Province is relatively good and its scale is large, also, the funds is guaranteed.

- The equipment and facilities are complete: Generally, the construction of schoolhouses, equipment and facilities of civilian-run colleges in Hubei Province is relatively complete.

- It has been founded for a long time, and it has distinctive features: The regulations, teaching staff and specialty characteristics of civilian-run colleges in Hubei Province are ensured, so the civilian-run colleges of undergraduate level in Hubei Province are all in the top 100 national civilian-run colleges.

- Teachers mainly work full-time and part-time complementarily: The colleges recruited some young doctors and master for teaching staff in recent years so that rejuvenation is guaranteed.

In summary, the features of civilian-run colleges and universities in Hubei Province are distinctive, the funds of running are sufficient, the level of teaching staff is relatively high and the equipment and facilities are relatively complete. Their level of running school is above average level of national civilian-run colleges. And the basic guarantee for construction of stereo-mode of public physical education selective courses is fulfilled. 


\section{B. Strong Support from Various National Policies}

In August, 2002, the Ministry of Education clearly stated that "In order to realize the goal of public physical education selective courses, classroom teaching, extracurricular sports activities and off-campus sports activities should be combined together", "Take purposeful, planned and organized extracurricular sports exercise, off-campus (social and field) activities, sports training and so on in the public physical education selective courses to form a course construction with organic connection of in-class and extracurricular activities, incampus and off-campus activities".

In November 12nd, 2013, the Third Plenary Session of the 18th Central Committee of the Communist Party of China has passed the Decision of the Central Committee of the Communist Party of China on Some Major Issues Concerning Comprehensively Deepening the Reform. It clearly pointed out on deepening the comprehensive education reform that "intensify physical education and extracurricular exercise to promote physical and mental health of adolescents and to strengthen their bodies", which is a spirit and requirement with significant practical meaning and profound influence and points out the direction of reform and development of school physical education in our country.

In January 22nd, 2014, the Notice of the Ministry of Education concerning printing and distributing Work points of the Ministry of education in 2014, emphasized that "strengthen the school physical education practically, and implement the plan of promoting the national youth physical fitness and promote the Sunlight Sports Activities widely."

The related national department issued relative policies concerning speeding up the reform of physical education and strengthening the extracurricular physical training, which provides strong support for the construction of stereo-mode of public physical education selective courses of civilian-run colleges in Hubei Province.

\section{Strong Guarantee of Teachers'Professional Qualities}

The strong professional qualities of physical education teachers, to a large extent, provide a strong guarantee for students to learn more about sports skills. It is surveyed that if physical education teachers participate in and guide extracurricular sports activities, the enthusiasm of students' participation will be greatly improved. The second part of the stereo-mode of public physical education selective courses refers to the extracurricular sports activities which are taken in the course system and guided by professional teachers. So, in order to ensure the learning effect of extracurricular sports exercise, physical education teachers need profound professional qualities. The distribution structure of the degrees and professional titles of physical education teachers fully proved that their knowledge and experience are enough competent to guide students to participate inextracurricular sports exercise, which also lays good technical and intellectual support for construction of stereo-mode of public physical education selective courses.

\section{Basic Guarantee of Sports Facilities of Colleges}

Sports facilities are the basic guarantee for implementing public physical education selective courses. Sufficient sports facilities lay a good foundation for diversified development of public physical education selective courses. Due to the full use of social resources, the capital investment of civilian-run colleges is better off. So they make great efforts to construct hardware facilities like sports stadiums and fields to make sports facilities more complete, which provides a basic guarantee for implementing stereo-mode of public physical education selective courses.

\section{E. Real Requirements of Students' Credit System}

At present, credit management is basically carried out in colleges in our country, which makes students take credit as their main purpose to attend public physical education selective courses and ignore the extracurricular sports activities without credit. In 8 civilian-run colleges in Hubei Province, if the extracurricular sports activities are taken in the credit system, $91.8 \%$ of students express that they will participate in or may participate inextracurricular sports activities, and only $3.7 \%$ of them won't jo in. It is not difficult to exp lain that if the extracurricular sports activities are taken in the credit system, students can participate in sports exercise and fulfill the requirements of credit management at the same time, which can provide a double advantage or even more advantages.

In the stereo-mode of public physical education selective courses, the implementation of the innovative credit management system not only fulfills the goals to do extracurricular sports exercise for students, but also improves the enthusiasm and initiative of students to a great extent. In other words, the real require ments of credit sys tem for students also lay a good foundation for construction of stereo-mode of public physical education selective courses.

\section{SUGGESTIONS}

\section{A. From Top to Bottom, Establish Rules and Regulations}

In the stereo-mode of public physical education selective courses, extracurricular sports activities are for the whole college, so it is crucial to obtain respect and support from school leaders. Moreover, under the special vertical management system in our country, the strength and efficiency of promoting the development of an activity from top to bottom can be improved more than that from bottom to top.

From the aspect of colleges, with great importance attached by school leaders, overall planning and coordinated development of the whole course mode will greatly improve the effective utilization of sports resources, and provide a necessary guarantee for the implementation of stereo-mode of public physical education selective courses.

Establishing complete and relative regulations is also an important measure to guarantee the implementation of stereomode of public physical education selective courses. The establishment of regulations should take not only restriction and motivation for students into account, but also the recognition and rewards for teachers' duties and workload. 
Complete regulations are for better grasping and controlling the implementation of the course mode, also for promoting the healthy development of the course mode.

\section{B. Get Rid of the Barriers, Work Together}

In the process of the implementation of traditional public physical education selective courses, the university or each college just needs to arrange the class hour of physical education according to the overall training programs for students. Then teachers of Physical Education Department arrange, organize and implement the course contents according to related course standards. Finally, students' scores will be fed back to each college by physical education teachers and then taken in the credit system

However, the stereo-mode of public physical education selective courses needs joint organization and management of the whole university and each college. It is required that each college or department should get rid of the barriers to guarantee the implementation of this course mode, strengthen mutual cooperation, create a smooth method of operation, participate in together and manage it together.

\section{Do Adequate Research, Arrange Classes According to Requirements}

In order to guarantee the effective implementation of stereo-mode of public physical education selective courses, to improve initiative of students' participation, exploit the essential function of sports and to avoid waste of sports resources meanwhile, colleges should make adequate investigations on many aspects, such as students' interest in sports, the number of the stadiums and the professional skills of physical education teaching staff, at the earlier stage of the implementation of stereo-mode of public physical education selective courses to gain detailed information and accurate data.

On the basis of comprehensive analysis, we should assess the sports requirements for students and the real sports resources, arrange the class projects and try to arrange the classes according to requirements, avoiding blindness of setting up projects. It can not only improve the pertinence and practicability of the stereo-mode of public physical education selective courses, but also provide direction for the development of this course mode.

\section{REFERENCES}

[1] Zhenming Mao. Brief discussion on the teaching of the elective course of Public Physical Education [M]. Beijing: Beijing Normal University Press, 2009:16.

[2] Wenxuan Yang, Ting Yang. Theory of physical education [M]. Beijing: Higher Educat ion Press, 2005:70-71.

[3] Yongzhong Zeng, Lunhong Dong. Research on the reform and construction of public physical education elective course system in higher vocational colleges [M]. Wuhan: Huazhong Normal University Press, 2009:86.

[4] Ming Wu. Investigations and analysis of college students' demand for physical education theory [J]. Shandong Sports Science \& Technology, 2001, 23(3): 43-45.

[5] Shaowei Pan, Kehong Yu. School physical education [M]. The second edition. Beijing: Higher Education Press, 2008: 178.
[6] Junhao Zhao, Junyong Zhang. Comparative analysis on teaching mode and curricular goal of physical education in Chinses and foreign universities in the new century [J]. Journal of Hubei Water Resources Technical College, 2001, 7(1): 37 . 